\title{
A comprehensive review on global contributions and recognition of pharmacy professionals amidst COVID-19 pandemic: moving from present to future
}

Saad Ahmed Sami ${ }^{\dagger}$, Kay Kay Shain Marma ${ }^{\dagger}$, Agnila Chakraborty ${ }^{\dagger}$, Tandra Singha, Ahmed Rakib, Md. Giash Uddin, Mohammed Kamrul Hossain and S. M. Naim Uddin ${ }^{*}$

\begin{abstract}
Background: COVID-19, a respiratory tract infection caused by SARS-CoV-2, is a burning question worldwide as it gives rise to a pandemic situation. No specific medications are still recommended for COVID-19; however, healthcare support is crucial for ameliorating the disease condition. Pharmacists are the frontline fighters who are responsible for providing healthcare support to the COVID-19 infected patients around the world. This review endeavored to briefly rationalize the contributions of several pharmacy professionals in diverse fields along with their collaborative efforts and dedication regarding their limitations during the COVID-19 situation and view the prospects of pharmaceutical care services in the post-pandemic period.

Main body of the abstract: Online databases were utilized to search for scholarly articles and organizational websites, to sum up the information about the contemporary and expanded role of pharmacists. Key articles were retrieved from Google Scholar, PubMed, and Science Direct databases using terms: "COVID-19," "novel coronavirus," "community," "industrial," "hospital," "clinical," "recognition," "obstacles," "collaboration," "SARS-CoV2," "healthcare," and "outbreak" in combination with "pharmacist." The articles were included from the inception of the pandemic to January 25, 2021. The current review found pharmacist's global contributions and involvements with other professionals to provide healthcare services amidst COVID-19. This included testing of suspects, providing medical information, psycho-social support, debunking myths, mitigating drug shortage events, telemedicine, e-prescription, infection control, and controlling the drug supply chain. In many countries, pharmacists' activities were much appreciated but in some countries, they were not properly acknowledged for their contributions amidst COVID-19 outbreak. They played additional roles such as participating in the antimicrobial stewardship team, improving value-added services, conducting clinical data analysis to suppress the outspread of the SARS-CoV-2.
\end{abstract}

\footnotetext{
* Correspondence: pharma.naim@cu.ac.bd

†Saad Ahmed Sami, Kay Kay Shain Marma and Agnila Chakraborty contributed equally to this work.

Department of Pharmacy, University of Chittagong, Chittagong 4331, Bangladesh
}

SpringerOpen

(c) The Author(s). 2021 Open Access This article is licensed under a Creative Commons Attribution 4.0 International License, which permits use, sharing, adaptation, distribution and reproduction in any medium or format, as long as you give appropriate credit to the original author(s) and the source, provide a link to the Creative Commons licence, and indicate if changes were made. The images or other third party material in this article are included in the article's Creative Commons licence, unless indicated otherwise in a credit line to the material. If material is not included in the article's Creative Commons licence and your intended use is not permitted by statutory regulation or exceeds the permitted use, you will need to obtain permission directly from the copyright holder. To view a copy of this licence, visit http://creativecommons.org/licenses/by/4.0/. 
Short conclusion: During the COVID-19 pandemic while the whole world is fighting against an invisible virus, the pharmacists are the earnest hero to serve their responsibilities along with additional activities. They need to be prepared and collaborate with other healthcare professionals further to meet the challenges of postpandemic circumstances.

Keywords: COVID-19, Pharmacist, Community, Hospital, Clinical, Industrial, Collaboration, Recognition

\section{Background}

The world has witnessed unprecedented outbreaks of many life-threatening viral diseases caused by an array of pathogenic organisms in the last few decades including Ebola, SARS (severe acute respiratory syndrome), MERS (Middle East respiratory syndrome), Chikungunya, and Influenza. In late December of 2019, a cluster of febrile respiratory cases greatly resembling viral pneumonia with unknown etiology was reported by the Chinese authorities. The metagenomic RNA sequencing of the pathogenic agent and the bronchoalveolar lavage fluid samples isolated from the patients identified a novel strain of human beta-coronavirus designated as severe acute respiratory syndrome coronavirus 2 (SARSCoV-2). The clinical condition caused by this causative agent is referred to as COVID-19 [1]. The spreading of the novel coronavirus (COVID-19) has been exponential that was not globally anticipated earlier. The devastating impact of this fatal outbreak has surpassed several viral infections we previously encountered and has become the center of global attention. Originating from Wuhan, one of the populous Chinese City of Hubei province in late December of 2019, this acute respiratory infection has deployed a significant toll on people across the globe in a short period and compelled the World Health Organization (WHO) to declare this outbreak as a pandemic on March 11, 2020 [2]. As of February 21, 2021, more than 110 million infected cases with over 2.4 million deaths have been reported worldwide [3].

COVID-19 is the third coronavirus outbreak of the twenty-first century and zoonotic origins like its predecessors (SARS, MERS). This virus can be transmitted via direct close contact and fomite transmission. Although symptoms generally appear but can also be asymptomatic that makes it even more dangerous. The symptoms of this viral infection may range from mild or moderate fever to severe pneumonia. The most common symptoms include combinations of fever, dry cough, loss of smell or taste, sore throat, and shortness of breath. Immunocompromised old-age patients with multi-organ failure and comorbidities are more susceptible and experienced the worse outcomes [4]. This viral infection has upended the global healthcare system by putting pressure on healthcare professionals and increasingly straining the supply of qualified healthcare providers. As COVID-19 is a contagious infection, there is a significant risk for healthcare professionals to be infected by this viral disease [5]. Watson and his team conducted a Delphi study that corroborated the competent role of pharmacy professionals in disaster management. Pharmacists can carry out their responsibility through direct or indirect patient contact and play a significant role in disease containment and management [6]. It has been well recognized that the commendable efforts and extraordinary performances were shown by the pharmacists in previous health and disaster crisis, for example, Zika, Ebola, H1N1 influenza, measles attack, anthrax crisis, and opioid crisis have made them an integral part of the healthcare team $[7,8]$. A USA-based study reported that, more than $85 \%$ of public health programs involve pharmacists in the vaccine distribution plans during pandemic situation [9]. During the 2009 H1N1 influenza pandemic, it was considered a convenient place for many patients to receive vaccinations [10]. In the event of any global epidemic, 93 percent of pharmacists at that time were able to maintain their services [11]. In Australia, within just 2 years, pharmacists have administered more than 35,000 influenza vaccines and Canadian pharmacists provided over 765,000 vaccinations in their pharmacy premises [12]. Pharmacies have become the most commonly used non-medical setting for flu vaccination in adults due to convenience and lower cost [13].

Though pharmacists contributed to previous pandemics but this time it is more difficult than before as the novel coronavirus is intractable, no vaccine or therapeutic guideline found and it suddenly manifested even without any precautions taken earlier on. Amid the public health crisis of current magnitude, pharmacists are adopting innovative strategies and working at the forefront alongside physicians, nurses, paramedics, and nontechnical staffs to combat the chaos attributed to the COVID-19 infection [14]. Being part of an interdisciplinary team, pharmacists play a vital role in helping patients and doctors interact better [15]. They remain the most reliable, accessible, and convenient professional for patients to provide medication service [16]. It has been over a year, pharmacists across the globe are carrying out their responsibilities for the betterment of the current situation. Pharmacists can play a potential role in this crisis time along with other healthcare workers.

In our current study, a literature search was performed to summarize the knowledge on the contribution of 
pharmacy professionals during the COVID-19 pandemic. The relevant articles were retrieved mainly from electronic databases including Google Scholar (https:// scholar.google.com/), PubMed (https://pubmed.ncbi. nlm.nih.gov/), and Science Direct (https://www. sciencedirect.com/). We conducted our search using the following terms: "COVID-19," "novel coronavirus," "community," "industrial," "hospital," "clinical," "recognition," "obstacles," "collaboration," "SARS-CoV-2," "healthcare," and "outbreak" in combination with "pharmacist." The articles including implications of pharmaceutical care services during the COVID-19 period and relevant pre-pandemic data were also covered as much as possible. Original research articles, review articles, commentaries, editorials, letters to the editor, authentic guidelines on the management of novel coronavirus pandemic, and official web pages of different pharmaceutical organizations were included in this study from the inception of the pandemic to January 25, 2021. Poster papers, advertisements, thesis works, preprints, and published studies in non-English languages were excluded from this study. The available materials were assembled carefully to point out the contemporary and expanded role of pharmacists across the world during the COVID-19 outbreak. The purpose of this review is to describe the global contributions of pharmacy professionals in different settings, their collaborative efforts, worldwide recognitions, limitations during the COVID19 situation, and prospects of the pharmaceutical care services in the post-pandemic period (Fig. 1).

\section{Contributions of community pharmacists in COVID-19}

Community pharmacists are healthcare providers who play vital roles in responding to symptoms, supplying medicines, and providing health promotion in the communities where they serve. They are being recognized not only as health professionals but also educators and counselors of patients, mentors and researchers, creative business formulators and developers, managers and leaders, and stakeholders [17]. They are the most accessible healthcare provider and a primary focal point for consumers to receive reliable evidence-based information when there is no hospital available nearby [18]. Community pharmacists are making essential public health contributions in rural areas where patients have to face obstacles such as acute shortage of primary care providers without proper facilities, hazardous terrain, and lack of public transportation with extended time in

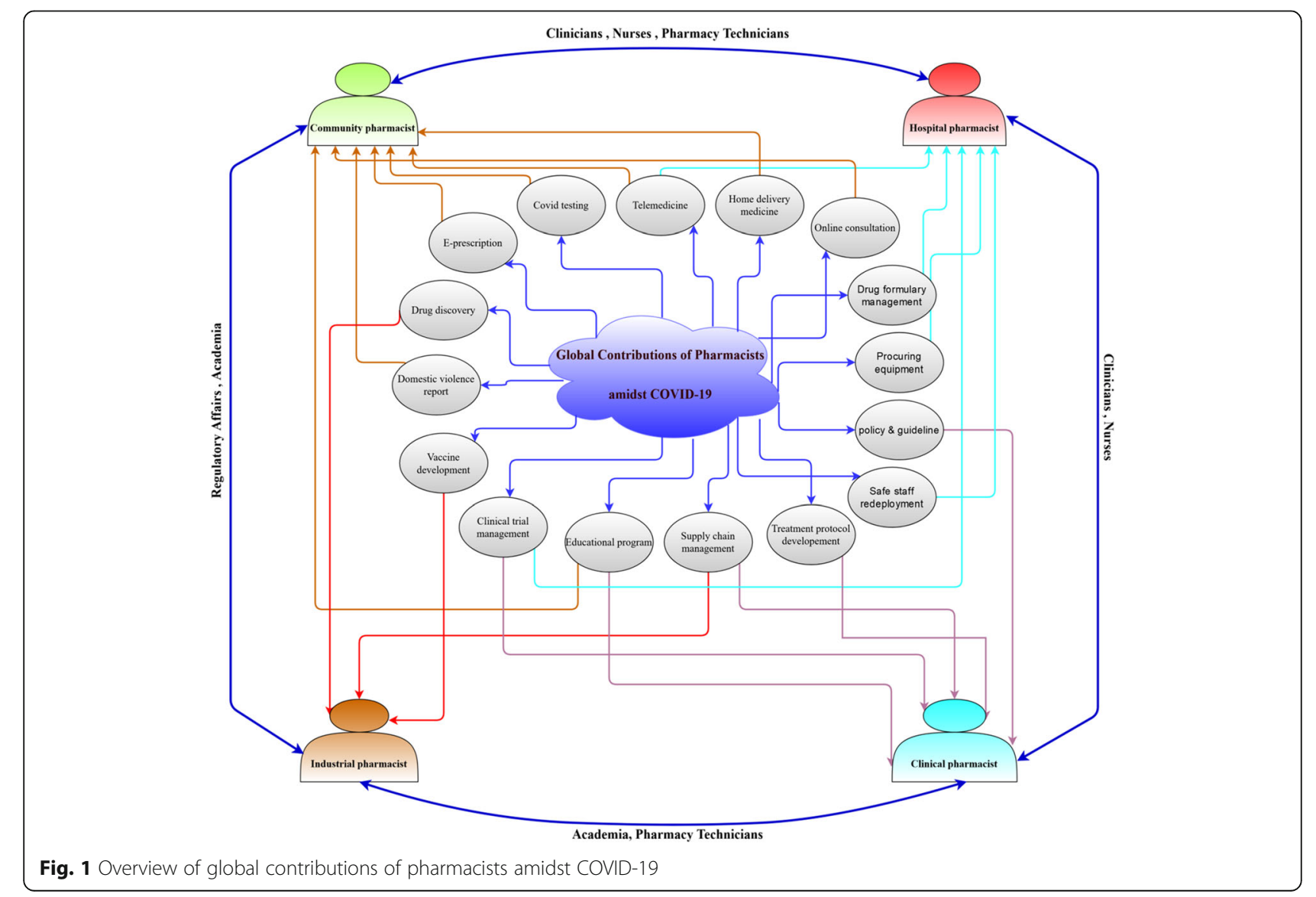


traveling that force them to postpone the needed health services [13].

Pharmacy care services during COVID-19 were divided into two categories; one was prevention and control of the pandemic and the other was to provide pharmacy services to the patients. Community pharmacy management teams supported primary care services by providing an adequate supply of COVID-19 related medications and preventative products, following environment regulations, and providing sufficient staff training. Pharmacists have used various approaches to provide primary care services in drug dispensing, consulting and referrals, chronic disease management, safe use of infusions, patient education, home care guidance, and psychological support to promote the COVID-19 pandemic control and ensure safe medication use of community patients during the pandemic [19]. Community pharmacies were one of the few places which remained open 24 $h$ daily amidst the heat of the total global lockdown to serve the populace [20]. During the current pandemic, it is recognized that community pharmacies will often be the first point of contact with the health system for individuals with COVID-19 related health concerns or who require reliable information and advice [14]. If an effective vaccine is developed to prevent COVID-19 infection, community pharmacists will be accessing healthcare providers to offer this immunization as evidenced by the growing number of patients receiving their influenza vaccine at local pharmacies. Pharmacists have been providing vaccinations services throughout the last few decades in the countries like the UK, New Zealand, Canada, and Portugal [21]. In the USA, community pharmacies are positioned as the second most utilized site for adult influenza vaccine administration after physician's chambers [22]. Hoti et al. reported about $90 \%$ of community pharmacists having specific knowledge for the implementation of COVID-19-related preventative measures. This evidence can be backed up by Chin and his colleagues who described the active role of Canadian pharmacists in SARS outbreak [17].

Many countries are leveraging a range of community pharmacy services where pharmacists are playing a pivotal role in controlling community transmission by educating the public and clients about COVID-19 signs and symptoms, offering counseling on COVID-19 precautionary measures including practicing social distancing, maintaining strict hand hygiene, avoiding touching facial $\mathrm{T}$-region (nose, eyes, mouth). They have taken the responsibility of keeping the record of contact-tracing history, disinfecting surfaces of pharmacy premises regularly, and also triaging at the community level for suspected COVID-19 cases [23, 24]. In many countries, community pharmacies have expanded service-hours amidst strict lockdown period intending to promote medication adherence, handle out-of-hours emergency supply requests, deterring misinformation, providing medical supply pharmaceutical products and devices (face masks, over-the-counter drugs, disinfectants), and thus reducing the burden of general practice, unnecessary hospital visits, and health expenditure [25-27]. Amariles et al. recently depicted the critical role of pharmacists in minimizing community transmission of the COVID-19 virus by ensuring appropriate detection, referral, and suspected case management [28].

The review of health services provided by the community pharmacists in different countries across continents amidst COVID-19 would make it more evident. In many developed countries (USA, Spain, France, Canada, Denmark, Italy, Netherlands, Scotland, and Germany), community pharmacists leveraged on information communication technology to minimize direct patient contact and deliver essential pharmaceutical care services [29]. Recently, a study in Macau has demonstrated the importance of community pharmacist's participation in the COVID-19 management system, where they were given the charge of maintaining overall infection progress and government approach "The Guaranteed Mask Supply for Macao residents Scheme" [30]. In Saudi Arabia, pharmacists delivered medications by mail with continuous counseling to keep the patients safe at home [31]. In many European countries, community pharmacists took part in the domestic violence campaign where they had the authority to report complaints [32]. In African countries, the diagnostic testing for the COVID-19 infection is a massive challenge due to the fragile healthcare structure of the region [33]. But even in some of those countries, community pharmacists are executing their duties to the best of their abilities [20, 29, 34].

Community pharmacists have provided crucial services to tackle the COVID-19 health crisis in many countries across the continents which are described briefly in Table 1.

\section{Contributions of hospital pharmacists in COVID- 19}

The ongoing COVID-19 pandemic has increased the responsibility of hospital pharmacists as they had to take care of the COVID-19 patients in hospitals and control the pandemic emergency. Their role cannot be overlooked as they directly contributed to COVID-19 management protocols alongside ICU (intensive care unit) nurses, physicians, and respiratory therapists. Participating in the antimicrobial stewardship programs makes them directly involved in planning and responding to pathogen outbreaks. These responsibilities also help them in determining the safety and effectiveness of new antiviral drug treatment [45]. They supported pharmaceutical care services and participated in the COVID-19 
Table 1 Services provided by community pharmacists in tackling COVID-19 health crisis

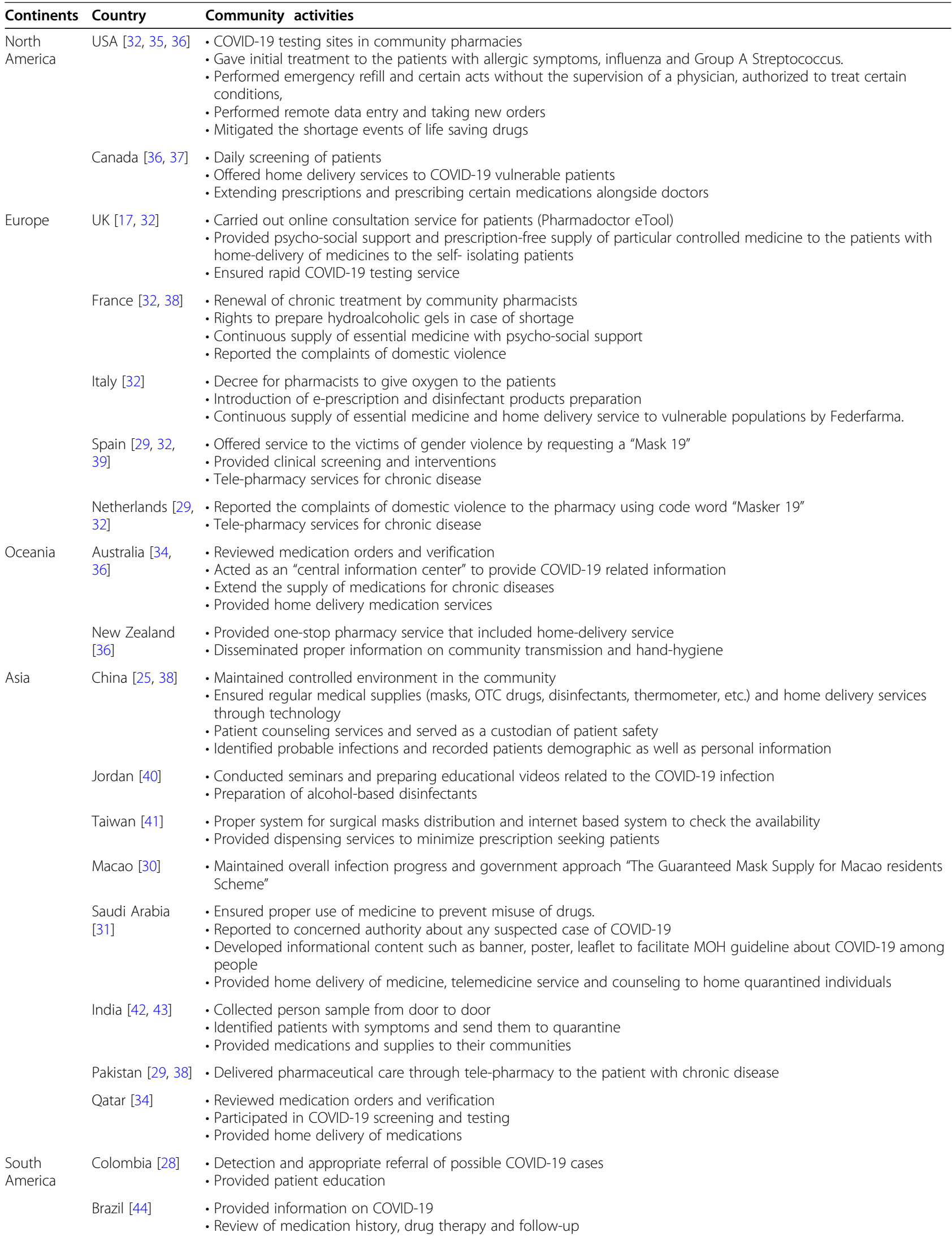


Table 1 Services provided by community pharmacists in tackling COVID-19 health crisis (Continued)

\begin{tabular}{lll}
\hline Continents & Country & Community activities \\
\hline Africa & Nigeria $[20,34]$ & $\begin{array}{l}\text { - Medication adherence guidance in acute and chronic disease } \\
\text { - Reviewed medication orders and verification }\end{array}$ \\
& Egypt $[29]$ & - Delivered pharmaceutical care through tele-pharmacy to the patient with chronic disease \\
South Africa & - Extend the supply of medications for chronic diseases \\
[34] & - Reviewed medication orders and verification \\
Kenya [20] & - Advocated zero-tax implementation on drugs to ensure drug affordability \\
\hline
\end{tabular}

medical collaborative team to facilitate pandemic control by developing strategies to tackle drug shortages, ensuring the safe transition of care via medication reconciliation, reviewing treatment charts, and giving emotional support to the comorbid patients. Besides, they are disseminating information on prevention, detection, treatment of managing COVID-19 infections, and offering continuous healthcare service to patients with chronic diseases in hospitals. They have also combined clinical guidance and clinical research to help physicians in formulating drug regimens [46-49]. In Middle East and South Asia, pharmacy workflow was redesigned in many hospitals. Outpatient pharmacies of some hospitals removed many chairs from the waiting room areas to promote social distancing. Additionally, the deactivation of fingerprint access was made for all devices with the use of biological identification technology [50]. The most challenging task was to procure emergency and alternative medicines, assessing the drug shortage, and reserving repurposed drugs for COVID-19 treatment [6]. Proper pharmacovigilance to identify and minimize serious adverse effects and drug interactions among the different new COVID-19 drugs has been carried away by the hospital pharmacists. In particular, corticosteroids were used for patients with respiratory problems but not recommended in viral pneumonia [51].

Because of the restricted availability of personal protective equipment (PPE) in most hospitals, the existence of the pharmaceutical services provided by hospital pharmacists often made them vulnerable to infection regularly. For instance, a window-dispensing method was adopted by many community and hospital pharmacies where doors were shut, and helmet was used as a shield to cover the face to ensure adequate pharmaceutical care service in Nigeria [52]. Furthermore, Hospital pharmacists played a crucial role in the enrollment of infected patients for clinical-trial studies [23].

The highlights of hospital pharmacist's activity in different countries are the following:

\section{United States of America}

In the USA, pharmacists of the American Society of Health Systems pharmacists (ASHP) supported other healthcare providers by enhancing the safe use of medications and improving patient outcome [34]. During the virtual and hospital bedside rounds, they provided medication recommendations, drug information to the healthcare professionals, delivered education, and information to assist the patients with their lifestyle choices upon admission or discharge. Elson et al. published a report involving healthcare professionals and pediatric patients in the hospital and ambulatory pharmacy. According to them, pharmacists have contributed to adequate storage and drug supply by making phone calls not only to outside pharmacies but also to patient families and insurance companies. They conducted virtual rounds by reviewing patient's profiles in the EMR (electronic medical report) to ensure safety efficacy of medication therapy, carried away formulary and inventory management through emails, conference calls, Microsoft teams, and provided ambulatory care services remotely. Zuckerman et al. also published a report on healthcare professionals where COVID-19 and non-COVID-19 patients in hospital and ambulatory pharmacy setups where the pharmacists worked on staff redeployment and modifications, counsel patients with COVID-19 on suspending therapy due to immunosuppression, and transition of therapy or treatment procedure [53].

\section{China}

The first guidance and protocols for hospital pharmacy procedures were described in the "Recommendations on Hospital Pharmacy Departments Coping with Corona Virus Disease 2019" (2nd edition) prepared by the Beijing Pharmacy Center for Quality Control and Improvement [25]. A study in Northeast China has shown the efficiency of hospital pharmacists in controlling nosocomial infections and medication errors during the COVID-19 pandemic [54]. Hospital pharmacists also provided direct healthcare services at cabin hospitals of Wuhan, China, where mild cases of COVID-19 infected patients were quarantined and treated effectively [49]. During the ongoing pandemic, the pharmacists in Peking University Third Hospital discussed the role of hospital and community pharmacists and the components of pharmaceutical care [55]. Hua et al. and Meng et al. 
conducted their respective studies on healthcare professionals and COVID-19 patients in the hospital where pharmacists helped in managing drug formulary, purchase, storage and distribution, loading trolleys with critical care drugs, establishing new pharmacy arrangement, procuring equipment, providing drug information to healthcare professionals, etc. Additionally, Tan et al. published an article on patients undergoing warfarin therapy where hospital pharmacists helped in managing warfarin dose adjustment and change of therapy [53].

\section{Canada}

Pharmacists in Public Health Ontario (PHO), Hotel Dieu Shaver Health and Rehabilitation Centre (HDSHRC) started combining the drug administration time for reducing the use of PPE and minimizing exposure between patients and healthcare providers. Pharmacists shared advice on the appropriate use of MDI (metered dose inhalers), nebulizers, and other intra-nasal drugs in COVID-19 patients. They also monitored the proper use of antibiotics. Canadian Society of Hospital Pharmacists (CSHP) introduced an expanded network of educational videos, links, and other resources to COVID-19 specialty hospitals and other collaborative care giving settings [34, 56].

\section{Australia}

Hospital pharmacists in Australia were directly involved with redesigning COVID-19 specific hospital wards and gathering dedicated teams for the treatment. Within a week, they expanded the existing 7 days a week clinical pharmacy facility of ICU and general medical unit to a 24 h service. Society of Hospital Pharmacists Australia (SHPA) started COVID-19 information hub with other pharmacy departments for sharing information and queries for professional development [34].

\section{Saudi Arabia}

Saudi Pharmaceutical Society (SPS) published a report on COVID-19 and its management. During the rudimentary phase of the pandemic in Jeddah at King Abdulaziz University (KAU) and Hospital (KAUH), a COVID19 patient rounding team consisting of ID (infectious disease) physicians and ID pharmacists was established. Pharmacists, pharmacy technicians, and students all helped in improving pharmacy care services for COVID19 in the in-patient and out-patient settings [34]. "Drivethrough pharmacy" service has been launched in several hospitals of Saudi Arabia where the hospital pharmacist reviews the prescription and ascertains doses just after the doctor gave the prescription through telephone or online consultation and handed medicines through postal delivery [31].

\section{Qatar}

Hamad Medical Corporation (HMC) in Qatar consisted of 12 general and specialized hospitals were led by more than 400 pharmacists and pharmacy technicians. They showed extraordinary dedication and efficiency during the COVID-19 outbreak. Pharmacists also provided drive-through and tele-pharmacy services [34].

\section{South Africa}

The pharmacists of Netcare Hospital Group Ltd., a network of 54 private hospital played an important role by providing services like maintenance and supply of crucial medications for COVID-19 patients, preparing material packs for surgical items, e.g., ventilation packs, catheter packs, admission packs, and medication packs for prompt and continuous supply within wards. Also, pharmacists have monitored the COVID-19-related treatment regimen. A Monitored Emergency Use of Unregistered Interventions (MEURI) study was designed by a pharmacist for safe and effective monitoring of patients receiving off label therapeutics of COVID-19 in a hospital outside the clinical trial, recommended by the WHO and the South African National Department of Health (NDoH) [34, 57].

\section{Nigeria}

Pharmacists at the University of Nigeria Teaching Hospital being an integral part of the newly launched frontline testing team and treatment center played a vital role by prescription filling, monitoring, and managing medication stewardship of antibiotics, immune boosters, and over used anti-viral agents when there was no official treatment regimen for COVID-19 treatment [34].

\section{Lebanon}

Knowledge and preparedness of pharmacists toward COVID-19 pandemic across Lebanon was surveyed by an English-based online questionnaire through social media platforms, e.g., Whatsapp, Linkedin, and Facebook. Results showed participants had more than 90\% knowledge about COVID-19, almost 67\% were maintaining safety recommendations. Despite facing shortages, increased prices, delayed supply of masks and sanitizers, $50 \%$ of hospitals had taken immediate practical steps during the pandemic outbreak [58]. Despite facing economic and political unrest, Lebanese pharmacists have played key roles on the frontlines of the COVID-19 pandemic in community, hospitals, and academic fields since the first case on 21 February, 2020 [59].

\section{Spain}

Spanish Society of Hospital Pharmacy (SEFH) supported research by creating its own Research Committee and taking part in clinical trials. The Spanish Agency for 
Medicines and Medical Devices (AEMPS), along with the Institutional Review Boards adopted a fast-track review procedure for accelerating approvals for clinical trials of COVID-19 treatment. From 176 recorded clinical trials in the European Union Clinical Register, Spain ranked first by conducting 68 clinical trials, the second was France with 42 clinical trials followed by the UK with 28 clinical trials. Funding is crucial to conduct clinical trials and research and initiative like "Caixaimpulse COVID-19" launched by La Caixa Foundation, in Spain and Portugal supported clinical and translational research projects with a budget of 1.5 million euros for the use of new technologies for the COVID-19 prevention, management, follow-up, and diagnosis [60].

\section{Miscellaneous}

In the UK, pharmacists in the hospital had to work beyond their usual duties including relocation to the intensive care unit, managing and monitoring COVID-19 patient clinical trials. Some UK pharmacists provided support to four African Commonwealth countries through Commonwealth Partnership for Antimicrobial Resistance and Commonwealth Pharmacists Association. Pharmacists also helped in developing COVID-19 medication protocols, identifying therapeutic drug alternatives, assisting with investigational drug administration, etc. [34]. A survey of pharmacists from 16 European countries including Belgium, Czech Republic, France, Italy, Northern Ireland, Switzerland, and Turkey showed that pharmacists in hospital setups helped in adjusting accommodation facilities, maintaining safe staff redeployment, and minimizing transmission, ensuring continuous medication, PPE and disinfectants supply, collaboration with inter personnel, etc. [39].

\section{Contributions of clinical pharmacists in COVID-19}

Clinical pharmacists are specially trained licensed practitioners who provide all types of direct patient care settings by utilizing their in-depth knowledge of medications [61]. Clinical pharmacy services offer an integrative healthcare system that optimizes comprehensive use of medicine for ambulatory and acute care patients by entailing both community and hospital [62]. The downside of COVID-19 exerted a lack of selfmanagement practices and poor medication adherence among patients with chronic diseases [29]. Clinical pharmacists play a pivotal role in developing innovative strategies and formulating work instructions to promote rational use of the drug with the collaboration of other healthcare professionals [24]. Amidst the heat of the COVID-19 pandemic, they provided a wide range of inpatient services including emphasizing dosage; multidrug therapy reviews; providing precise provision of patient assistance; monitoring off-level use of the drug, medication efficacy; or adverse drug reaction; attending clinical rounds; preparing discharge, and proper counseling of patients [63, 64]. Huibo $\mathrm{Li}$ et al. [55] summarized the activity of clinical pharmacists during COVID-19 as follows:

- Development of guidelines for the provision of pharmaceutical services

- Create directory and medical news

- Drug assessment based on proper evidence

- Analysis of remote orders and distribution

- Developing personalized treatment strategies

- Providing telehealth consultation and correct medical information to patients

Clinical pharmacists work as a mediator between physicians and patients and keep their knowledge up-todate on the latest information from federal agencies, such as the Centers for Disease Control and Prevention (CDC) to identify symptoms, carry out elementary screenings, and confirm individuals having relevant epidemiological risk factors [23]. They are also guiding outpatient dispensing services where there is a shortage of medications taken for autoimmune disorders chronically. In addition, they are minimizing the exposure of patients to COVID-19 by offering telemedicine services, transferring a prescription to mail orders, coordinating with external laboratory facilities, and remain in contact with patients receiving treatments in the clinic to address their concerns. Clinical pharmacists are also optimizing patient care by maintaining insurance coordination of self-monitoring equipment and infusion [65, 66]. Telemedicine service involving clinical pharmacists has some advantages including flexibility for scheduling chemotherapy, anticoagulant therapy, chronic pain prescription, and also special care diseases [67].

The services of a clinical pharmacist are not confined to only COVID-19 patients as there is a strain on the number of healthcare professionals. Cancer patients are immune-compromised and the critical environment of the hospital increases the exposure to COVID-19 infection. Pharmacist's role in guiding cancer patients amidst the current pandemic is of great importance as most cancer patients are needed to visit the hospital for a routine checkup and chemotherapy [62]. Clinical pharmacists have played a significant role in assisting the investigation of various novel experimental agents in controlled studies for the prophylaxis and treatment of COVID-19. They also facilitate patient assessment to ensure the favorable opinion of the Ethics Committee for the emergency use of the investigational new drug through compassionate use protocols [17]. They are also acquainted with the clinical trial management system where they actively co-operate with research sponsors, 
undertake inventories of research portfolio libraries, and evaluate the safety and efficacy of related trial drugs [68]. Gross et al. pointed out the critical role of clinical pharmacists in interpreting scientific literatures and approved drug information of other disease-states to provide substantial information to the clinicians and repurposed them for COVID-19. Pharmacists are conducting these experimental drug studies and helping drug discovery through sympathetic use protocols. In the USA, clinical pharmacists were actively engaged in the initial phase of remdesivir's clinical trial where they carried out a study for the clinical assessment process of the patient, kept previous medication history of the patient, participated in clinical decision making, and informed patient consent [35].

Luisetto indicated clinical pharmacist's association in achieving clinical improvement in many medical teams [17]. Leguelinel-Blache et al. depicted the role of ICU pharmacists providing bundled care services to 1164 patients with severe conditions which concluded a decrease in the length of stay and mechanical ventilation duration for the ICU patients along with the minimization of overall healthcare cost services by 10,840 euros [69]. Chinese clinical pharmacists monitored the action of lopinavir/ritonavir, ribavirin, glucocorticoids, and immunomodulatory drugs closely in the early period of COVID-19 because of their safety issues [70]. Karasneh et al. reported the expertise of pharmacists having good basic disease knowledge on COVID-19 [17]. It is expected that, when the vaccine will be available, clinical pharmacists may administer tests approved by the US FDA (The United States Food and Drug Administration) [37].

We highlighted the prime global activities of clinical pharmacists in Table 2.

\section{Contributions of industrial pharmacists and pharmaceutical companies in COVID-19}

The outstanding achievements of industrial pharmacists are getting unnoticed. They are the prime reason behind smooth services provided by other healthcare professionals. In the initial COVID-19 period, the bulk production of drugs was hampered and drug shortage events were observed globally as China and India-the main suppliers of active pharmaceutical ingredients (APIs) were unable to export products due to increased domestic API consumption. Moreover, the medicines used for COVID-19 treatment in hospitals including respiratory drugs and painkillers experienced an increase from 100\% to whopping $700 \%$ since the outset of the pandemic [75]. To meet this increased demand for medicines and medical devices, the industrial pharmacists had to work around the clock to scale up the manufacturing process that ensures smooth supply of proper medicines, surgical items, disinfectants, immune-modulators, and other related medicines. For instance, the production of surgical masks in Taiwan was rapidly increased to 13 million masks per day to allow the Taiwanese population to get the individual allowance of 10 masks every 2 weeks [41]. During clinical research, industrial pharmacists were often responsible for determining the ethical aspects and using the industry's successful tools [6].

Report showed $72 \%$ of confirmed vaccine projects had been being led with the aid of the private/pharmaceutical industry while the remaining $28 \%$ are managed by universities, the public sector, and other non-profit companies [76]. From decades of experience gained with previous epidemics, industrial researchers are utilizing their deep scientific knowledge to identify the potential of existing treatments for research and development. European industrial pharmacists are partnering with academics, neighboring and global companies, and life sciences sectors to find a way to save the world from further destruction of the ongoing pandemic [77].

The contributions of pharmaceutical companies during COVID-19 pandemic are highlighted in Table 3 [77].

\section{Significance of pharmacists' inter-professional and intra-professional collaboration in COVID-19}

From an ethical and professional perspective, interprofessional and intra-professional collaboration is significant to reduce inequalities and optimize the highest level of healthcare services. This collaboration becomes more critical amidst public health crisis like the current COVID-19 pandemic [17]. This pandemic is not the first health crises for the pharmacists to fight. A study in Saudi Arabia during MERS showed that pharmacists collaborating with primary healthcare providers in the treatment of severely ill condition patients played an enormous role in the clinical decision-making and medication management system. In that case, the pharmacist's knowledge of disease (88.9\%) was second-highest below the physicians (95.7\%) and had shown a positive attitude (94.4\%) toward the crisis [78]. Pharmacists are serving as frontline fighters alongside physicians, nurses, and non-technical staff to ensure better health outcomes [14]. The contributions of pharmacists in the correctional home of low- to middle-income countries during COVID-19 were also exemplary. Their activities ranged from providing treatment for minor diseases, disseminating the right information, preventing substance use disorder (SUD) to collaborating physicians of medical clinics in order to ensure better treatment of the inmates [79]. Klepser and his research team previously demonstrated the importance of the physician and pharmacist's collaborative efforts for timely treatment of influenzalike illness (ILI) [17]. Through remarkable collaboration, pharmacists of the UK (UK) and Pakistan have compiled 10-step protection guidelines both in English and Urdu 
Table 2 Global activities of clinical pharmacists in COVID-19 pandemic

\begin{tabular}{|c|c|c|}
\hline Continent & Country & Activities \\
\hline $\begin{array}{l}\text { North } \\
\text { America }\end{array}$ & USA $[34,71]$ & $\begin{array}{l}\text {-American College of Clinical Pharmacists (ACCP) made short documentary stories about COVID-19 related practice, infor- } \\
\text { mation, research, education, and leadership. } \\
\text {-Started a new ambulatory care COVID-19 clinic for management of patients after hospital discharge at Ohio, Columbus. } \\
\text {-Provided service via telephone calls and collected information by MPN-SAF TSS and DIPSS plus and updated the infor- } \\
\text { mation to the EMR before patient's next visit. } \\
\text {-A US ID pharmacist from Miami Florida along with other clinical ID pharmacist all over the world started online } \\
\text { platform, the IDstewardship.com blog and @IDstewardship social media profiles which are free and open access to over } \\
41000 \text { users. They provided reliable information during this pandemic. }\end{array}$ \\
\hline \multirow[t]{2}{*}{ Europe } & UK [34] & $\begin{array}{l}\text {-Along with Royal Pharmaceutical Society, United Kingdom Clinical Pharmacists Association started training webinars } \\
\text { and clinical resource hub and delivered relevant resources for clinical pharmacists. } \\
\text { - Helped in policy making, advocacy and national guidance for pharmacists. } \\
\text {-Facilitated in COVID-19 clinical trials, intensive care units (ICU). }\end{array}$ \\
\hline & France [72] & $\begin{array}{l}\text {-Besides taking care of COVID-19 patients, clinical pharmacists were involved in managing, analyzing and answering } \\
\text { questions on an online Q\&A hub (https://sfpt-fr.org/covid19) formed by French Society of Pharmacology and } \\
\text { Therapeutics. }\end{array}$ \\
\hline \multirow[t]{6}{*}{ Asia } & China [70] & $\begin{array}{l}\text {-Provided updated treatment protocols, drug information, new drug therapy report, and helped the physicians as } \\
\text { frontline caregivers by managing adverse drug reactions, dosing, drug-drug interactions, etc. } \\
\text {-Gave extra attention to particular patient population during the pandemic, e.g., elderly, pregnant, children, patients with } \\
\text { previous chronic illness. } \\
\text { - Monitored drug-drug interactions for safety concerns such as lopinavir, ritonavir, tocilizumab, interferon, glucocorticoids, } \\
\text { and immunomodulatory drugs. } \\
\text { - Provided pharmacovigilance research and remote virtual patient counseling. }\end{array}$ \\
\hline & $\begin{array}{l}\text { Saudi Arabia } \\
\text { [34] }\end{array}$ & $\begin{array}{l}\text {-Saudi Society of Clinical Pharmacy (SSCP) published an opinion paper on Pharmacists roles and responsibilities during } \\
\text { epidemics and pandemics in Saudi Arabia. } \\
\text {-A team of clinical pharmacists was involved in analyzing, publishing, updating and creating treatment protocols for } \\
\text { COVID-19 according to the dynamic changes of the pandemic situation. }\end{array}$ \\
\hline & Qatar [34] & $\begin{array}{l}\text {-A clinical pharmacist's team dedicated as the frontline responders for the new established COVID-19 hospitals situated } \\
\text { across Qatar and provided clinical interventions and partook in daily rounds. }\end{array}$ \\
\hline & Thailand [73] & $\begin{array}{l}\text { - Clinical pharmacist team provided tele-monitoring service on daily basis for every patient by using physician order entry } \\
\text { system. } \\
\text {-Co-operated with physicians and nurses for handling critical cases of COVID-19. }\end{array}$ \\
\hline & Lebanon [58] & $\begin{array}{l}\text { - Clinical pharmacists along with the hospital multidisciplinary teams played crucial and unique roles in this pandemic. At } \\
\text { American University of Beirut Medical Center (AUBMC), the ID pharmacist analyzed the information and research papers } \\
\text { to establish a local clinical guideline for management of COVID-19. } \\
\text {-As frontline caregivers the clinical pharmacists performed therapeutic monitoring of COVID-19 patients and reviewed } \\
\text { daily medication regimen }\end{array}$ \\
\hline & Pakistan [74] & $\begin{array}{l}\text {-Promptly adapted the national COVID-19 treatment guidelines and provided healthcare to COVID-19 as well as non } \\
\text { COVID-19 patients. } \\
\text {-Worked beyond their usual duties including, prescribing support, patients medication chart review, ward rounds, and } \\
\text { counseling. } \\
\text {-Took part in reviewing new updated guidelines and treatment regimen }\end{array}$ \\
\hline \multirow[t]{2}{*}{ Africa } & $\begin{array}{l}\text { South Africa } \\
\text { [57] }\end{array}$ & $\begin{array}{l}\text {-South African Society of Clinical Pharmacy (SASOCP) published a practice guide for clinical pharmacists presenting the } \\
\text { role of clinical pharmacist in COVID-19 }\end{array}$ \\
\hline & Nigeria [34] & $\begin{array}{l}\text { - Clinical Pharmacy Association of Nigeria (CPAN) started webinars about COVID-19 and its effect on daily work life. } \\
\text {-Department of Clinical Pharmacy, The University of Nigeria, Nsukka, Enugu was a part of the National Scientific Advisory } \\
\text { Committee for verifying newly established COVID-19 cure. } \\
\text { - Pharmacists from the Department of Clinical Pharmacy, in the Africa Resource Centre Nigeria Hub helped to design } \\
\text { receptive health supply chain systems for effective distribution of PPE and medicine for different states. }\end{array}$ \\
\hline Oceania & Australia [34] & $\begin{array}{l}\text { - Clinical pharmacists with the National COVID-19 Clinical Evidence Taskforce developed national, evidence based guide- } \\
\text { lines for the clinical care of COVID-19 patients. } \\
\text {.Provided clinical reviews for outpatients via Telehealth and remote counseling. }\end{array}$ \\
\hline
\end{tabular}

languages to reduce community transmission among the frontline pharmacists [38]. Additionally, industrial pharmacists of many European biopharmaceutical companies are working collaboratively with utmost dedication across the healthcare communities, utilizing leading scientific technology, manpower, and resources with concerted effort to find the best possible solution to combat
COVID-19 [80]. The vigilant contact and integrated collaboration of industrial pharmacists with hospital pharmacists are of utmost importance to control the drug shortage events [6]. In the COVID-19 clinical trial management system, pharmacists are working in collaboration with physicians, research sponsors, and local investigational drug services. It is anticipated that, 
Table 3 The contributions of pharmaceutical companies during COVID-19 pandemic

\begin{tabular}{|c|c|c|}
\hline Area & Company & Activities \\
\hline \multirow[t]{6}{*}{$\begin{array}{l}\text { Treatment } \\
\text { development }\end{array}$} & Alexion & $\begin{array}{l}\text { Developed a potential medicine against COVID-19 and it is currently on a phase III clinical trial in hospitalized } \\
\text { adult patients. }\end{array}$ \\
\hline & AstraZeneca & $\begin{array}{l}\text { R\&D teams have promptly started a project with the aim of discovering monoclonal antibiotics that will be } \\
\text { effective against novel coronavirus. }\end{array}$ \\
\hline & $\begin{array}{l}\text { Johnson \& } \\
\text { Johnson }\end{array}$ & J\& with collaboration are screening existing molecules and also new active compound against COVID-19 virus. \\
\hline & Pfizer & $\begin{array}{l}\text { Conducted a preliminary evaluation of some previously developed antiviral compounds and that suppressed the } \\
\text { replication of similar coronaviruses to SARS-CoV-2 in cultured cells. }\end{array}$ \\
\hline & Novartis & $\begin{array}{l}\text { Aimed for initiating a phase-III clinical trial of canakinumab among pneumonia patient caused by novel } \\
\text { coronavirus. }\end{array}$ \\
\hline & Amgen & $\begin{array}{l}\text { Collaboration with biotechnology company to design and develop antibodies that may become successful to } \\
\text { neutralize or inhibit the SARS-CoV-2 virus. }\end{array}$ \\
\hline \multirow[t]{5}{*}{$\begin{array}{l}\text { Vaccine } \\
\text { development }\end{array}$} & Seqirus & $\begin{array}{l}\text { Working with the University of Queensland to support the CEPI-funded COVID-19 vaccine program based on } \\
\text { molecular clamp technology. }\end{array}$ \\
\hline & Sanofi & Work is underway to use a previously developed SARS vaccine with their own recombinant DNA technology. \\
\hline & Pfizer & $\begin{array}{l}\text { Pfizer and BioNTech have teamed up to develop a BioNTech mRNA vaccine candidate to prevent COVID-19 } \\
\text { infection. }\end{array}$ \\
\hline & $\begin{array}{l}\text { Johnson \& } \\
\text { Johnson }\end{array}$ & $\begin{array}{l}\text { Expanding partnerships with the Advanced Biomedical Research and Development Authority (BARDA) and } \\
\text { establishing new partnerships with Beth Israel Diaconis Medical Center (BIDMC) to accelerate the development } \\
\text { of potential novel coronavirus vaccines. }\end{array}$ \\
\hline & MSD & $\begin{array}{l}\text { MSD announced three scientific initiatives, including two agreements with Themis Bioscience and IAVI to } \\
\text { develop a potential SARS COVID-19 vaccine, and a partnership with Ridgeback Bio leading the development of } \\
\text { new antiviral therapeutics. }\end{array}$ \\
\hline \multirow[t]{3}{*}{ Diagnostics } & $\begin{array}{l}\text { AstraZeneca \& } \\
\text { GSK }\end{array}$ & $\begin{array}{l}\text { GSK, AstraZeneca, and Cambridge collaborated to set up a new test lab at the University's Anne McLaren lab. } \\
\text { GSK and AstraZeneca are working together to provide process optimization assistance to UK National Test } \\
\text { Centers in Milton Keynes, Alderley Park, and Glasgow for COVID-19, and to provide expertise in automation and } \\
\text { robotics to support national test systems. }\end{array}$ \\
\hline & Roche & $\begin{array}{l}\text { They announced a new antibody test. It is an in vitro test that uses human serum and plasma taken from a } \\
\text { blood sample to detect antibodies and determine the body's immune response to SARS-CoV-2. }\end{array}$ \\
\hline & Takeda & $\begin{array}{l}\text { Working with other pharmaceutical authorities and companies through Europe's Innovative Medicines Initiative } \\
\text { (IMI), we leverage our joint expertise to diagnose COVID-19 and develop inhibitors to prevent future outbreaks. }\end{array}$ \\
\hline \multirow[t]{5}{*}{ Helping NHS } & Alexion & $\begin{array}{l}\text { The Alexion Charitable Foundation has donated funds to three non-profit partner organizations, including the } \\
\text { WHO COVID-19 Unity Fund. }\end{array}$ \\
\hline & AstraZeneca & $\begin{array}{l}\text { Offered } 9 \text { million masks to support healthcare professionals around the world in response to the COVID-19 } \\
\text { pandemic. }\end{array}$ \\
\hline & $\begin{array}{l}\text { Johnson \& } \\
\text { Johnson }\end{array}$ & $\begin{array}{l}\text { Donated } £ 1 \text { million, to London College of Hygiene and Tropical Medicine to guide public opinion on current } \\
\text { and potential future actions to curb and treat COVID-19, 30,000 bottles of important toiletries and hand cream } \\
\text { worth } £ 250,000 \text { for distribution to healthcare workers, NHS expert. }\end{array}$ \\
\hline & Novo Nordisk & Working with the NHS, we have opened a new helpline to support diabetics during the outbreak of COVID-19. \\
\hline & Takeda UK & Donated over $£ 100,000$ to patient organizations and charities in urgent need. \\
\hline
\end{tabular}

pharmacists will work in collaboration with health economists, epidemiologists, biostatisticians, policy-makers to evaluate the total medical and healthcare expenditures in the near future [17].

\section{Global recognition of pharmacists in COVID-19}

The role of pharmacy professionals vary across countries and their expertise is underestimated in some situations [81]. Canadian national survey of 2015 reported that pharmacists gained the recognition of $64.6 \%$ public, $57.4 \%$ nurses, and $38.9 \%$ physicians as vaccine providers. In the same year in Australia, almost 95\% of the patients were satisfied with the vaccination services provided by the pharmacists and were willing to return to the pharmacists in the future. Additionally, $97 \%$ of patients would recommend the service to others [12]. In a national survey, the Canadian Pharmacist Association (CPhA) found out $73 \%$ of pharmacists reporting an increase in verbal abuse and other form of harassment by patients since the beginning of the COVID-19 crisis. Asian Pharmacists of Chinese descent faced an additional burden of harassment and anti-Asian racism in many countries like the USA, the UK, and France as a result of the COVID-19 pandemic [82].

The government of New Zealand and Northern Ireland has acknowledged pharmacists by providing 
extra remuneration amidst COVID-19, while Canada's most populace province Ontario excluded pharmacists as part of the frontline workers [37, 83]. In Malaysia, a previous study reported an average of 6.1 medicationrelated complications for every resident in nursing homes. Pharmacists have a big role to play in curtailing such problems and ensuring the quality use of medicines [84]. But many hospitals in Malaysia have enlisted clinical pharmacists as "non-essential medical staffs" amidst COVID-19. It is disheartening for the pharmacists as the non-essential medical staff was prohibited from entering wards to minimize the risk of COVID-19 infection [85]. In fact, the government of many countries had not included them in the pandemic preparedness setting despite their active responses in previous pandemic situations [29]. The nature of pharmacist's duties made them exposed to this contagious infection since they are in direct contact with the patients and infection can be developed through pre-symptomatic and asymptomatic individuals. Importantly, several countries like the USA, the UK, Australia, New Zealand, Canada, France, Ireland, South Africa, Spain, and Turkey have recommended the use of PPEs and disposable gloves for pharmacists when dealing with suspected or infected patients. On the contrary, there was no mention of PPE for pharmacy personnel in Belgium [86]. In Pakistan, community pharmacists have confronted transmission risks as the space in pharmacy stores were limited and even in the city's largest pharmacy, pharmacists were not provided with proper PPE [87]. If they are not provided with proper PPE's, it will increase their vulnerability to this infection [38, 68]. Sadly, eight community pharmacy staffs died in Italy as they did not have access to PPE and were exposed to the COVID-19 infection [36].

It is also observed that the fear of contracting COVID19 led many community pharmacy workers to exhibit reluctance in the discharge of duties. Therefore, the safety of pharmacists is also of utmost importance [20]. Even before the emergence of COVID-19, a lack of recognition for pharmacy services was also observed. Pharmacists were not given enough value for their services by other healthcare professionals in the renal multidisciplinary team of a South African tertiary hospital [88]. In Western Australia, community pharmacists delivering vaccination services were also denied receiving any financial remuneration from the government [21]. Onozato et al. pointed out the significance of administrative and political support within healthcare institutions to maintain the quality of clinical pharmacy services [89]. Bauman demonstrated that pharmacists did not get proper acknowledgement during COVID-19 like other frontline fighters. Even though pharmacist's attributes are well known to physicians, respiratory therapists and nurses, the knowledge does not always get translated to the news media, general public, and politicians [90]. Pharmacists are the heroes behind the scenes who should be addressed and given the recognition they truly deserve.

\section{Obstacles to pharmacy services during COVID-19 and future prospects}

Stress and anxieties are part of normal human reactions in crisis moments. Pharmacists are not beyond these as they had to play a dual role of healthcare givers and retailers [91]. The current pandemic has caused extraordinary and prolonged demands on the whole healthcare system and caregivers [92]. In order to manage the preexisting community needs, pharmacists had to adapt to the new challenging and dynamic healthcare regulations. They had to deal with the intensified anxiety and stress because of the workloads, risk of infection and transmission, aggressive patients, and financial aspects of the pandemic. Clinical pharmacists were stuck in a catch-22 situation where they wanted to deliver healthcare services to the patients but lacked proper support to deliver healthcare. A study concluded that pharmacists experienced the highest rate of burnout due to excessive workloads compared to physicians and nurses even before the beginning of this pandemic period [60, 93]. Despite appropriate recommendations made by the clinical pharmacists, physician's reluctance to alter their colleague's prescriptions adversely affected the role of pharmacists in a multidisciplinary team [94]. During COVID-19, pharmacists in Canada had spent $24 \%$ of their shift in dealing with medication shortages which placed a huge burden. Additionally, a USA-based survey study in nine major hospitals across the country indicated fewer patients were interested in seeking healthcare in hospitals due to the fear of infecting COVID-19. Instead, they went to the community pharmacists to receive guidance leading to a strain in the community pharmacist's role as they had to fill the clinical role to some extent. Besides dealing with technical difficulties, pharmacists also encountered ethical dilemmas in prioritizing one patient over another. This is also detrimental to the mental well-being of a pharmacist. Pharmacists have faced risks and anxieties in their personal lives outside their professional lives because of lack of childcare, chances of infecting other family members, regular social interactions, and leisure time that are adaptive methods to deal with stress $[82,95]$.

In low- and middle-income countries (LMICs), the healthcare system had already struggled with many multifactorial challenges and barriers like substandard patient care quality, limited access to the world health system, drug shortage, insufficient health professionals, inadequate financial support, and limited budget. The 
current pandemic has aggravated these crises and challenges. However in LMICs, the core responsibility and duties of pharmacists being limited to drug dispensing, providing medication information and counseling, and monitoring interaction among drugs [96, 97]. For instance, the government of Pakistan provided inadequate attention to the pharmacy sector as a frontline caregiver and regulated community pharmacy as a regular commercial unit [98]. Due to a lack of appropriate practical, clinical research opportunities and knowledge of advanced technology and pharmacy services, fresh pharmacy graduates could not contribute much to this COVID-19 pandemic [99]. A study conducted by the pharmacists in Egypt displayed that Egyptians had confidence on their healthcare system as they immediately implemented intensive and affective measures to combat the pandemic situation [100]. Pharmacists of low- and middle-income countries were also keen on attending online webinars and workshops, following WHO guidelines regularly to understand new strategies to utilize drug reconciliation and patient counseling. The first COVID-19 webinar arranged by Commonwealth Pharmacists Association (CPA) saw the participation of 620 pharmacists from 38 countries where the top five registered countries (Nigeria, Kenya, Malaysia, India, and Pakistan) were from LMICs. Despite facing numerous difficulties, pharmacists (hospital, clinical, and community) of LMICs had come forward as frontline caregivers to manage the increasing challenges and limitations related to the pandemic $[16,83]$.

However, from the literature review, it is evident that pharmacist has carried away their responsibilities despite many obstacles like supply shortage, rapidly changing policies, recommendations, treatment design, increased burden on the health system, and also difficulties in direct patients-pharmacists communication due to risk of transmission. In many countries, laws and regulations for the pharmacy practice had been immediately adapted which gave the pharmacists their long due scope and opportunities to serve the patients and to demonstrate that their contribution is valuable to the healthcare system [101]. Cadogan and Hughes described frameworks for pharmacists in the UK and Canada, where pharmacists can evaluate and manage patients according to the preexisted formulary and drug scheduling models for their minor ailments during a time of routine check-ups or rounds if physicians are unavailable or reduced [27]. Meantime, different value-added services (VAS) provided by pharmacists have become popular which can be useful in healthcare services in the future. Drive thru pharmacy, has become widely accepted in the USA, the UK, Malaysia, Taiwan, Jordan, Croatia, Australia, and many other countries. Rolls Royce service, chronic illness card, forward dispensing, one-stop-shops, prescription reminder, home delivery services, the clickand-collect technology, the Hub and Spoke dispensing models, supplementary prescribing, the ATM-style prescription collection point, and independent prescribing models are some of the VAS used in Australia, UK, and many other countries. Some of these services started before the COVID-19 but during the pandemic era became more popular. Digitalization and the use of technology in the pharmacy sector even after the COVID-19 may enable better healthcare services and ensure a healthier life for everybody [102].

\section{Limitations of the review}

This review included only those activities by pharmacists that were performed for managing COVID-19 situations and did not consider the regular activities of pharmacy professionals. All the articles related to our study of interest may not be covered due to not being indexed in the databases we searched or being available at different websites. Besides, the published articles on COVID-19 are increasing on a regular basis and some articles may miss out as they may be available after the established search time period. This review did not explore the quality of the published papers taking into account but aimed to signify the dedication and engagement of pharmacy professionals being a part of the frontline savior team.

\section{Conclusion}

COVID-19 pandemic has not only been a pronounced challenge and burden on the healthcare system that the human race experienced together all over the world but it has also opened up new doors that have changed the structure of the global healthcare system. Adaptation of new situations, a gradual extension of existing knowledge and skills are in a need for all healthcare professionals, especially for the frontline healthcare service providers. The way of providing pharmaceutical care has been entirely changed during this pandemic, and pharmacists all around the world are concerned about the new regulations, systems, and services. Pharmacists are taking more responsibilities to reduce and control this pandemic. They are now included in more engaging positions at healthcare services by many countries emphasizing the importance of pharmacists. In less developing countries, pharmacists are working without proper safety measures and are unable to utilize their full potentials as they are not provided all the support needed. The regulatory affairs, policy-makers, and academics should come forward to design more suitable models to utilize their competence and increase the workflow of the patient care services. 


\section{Abbreviations}

SARS: Severe acute respiratory syndrome; MERS: Middle East respiratory syndrome; SARS-CoV-2: Severe acute respiratory syndrome coronavirus 2; WHO: World Health Organization; PPE: Personal protective equipment; ID: Infectious disease; ICU: Intensive care unit; SUD: Substance use disorder; ILI: Influenza-like illness; CPA: Commonwealth Pharmacists Association; API: Active pharmaceutical ingredients; CPhA: Canadian Pharmacists Association; EMR: Electronic medical report; ASHP: American Society of Health Systems pharmacists; PHO: Public Health Ontario; HDSHRC: Hotel Dieu Shaver Health and Rehabilitation Centre; MDI: Metered dose inhalers; CSHP: Canadian Society of Hospital Pharmacists; SHPA: Society of Hospital Pharmacists Australia; SPS: Saudi Pharmaceutical Society; KAU: King Abdulaziz University; KAUH: King Abdulaziz University Hospital; HMC: Hamad Medical Corporation; MEURI: Monitored emergency use of unregistered interventions; NDoH: South African National Department of Health; SEFH: Spanish Society of Hospital Pharmacy; AEMPS: The Spanish Agency for Medicines and Medical Devices; CDC: Centers for Disease Control and Prevention; US FDA: The United States Food and Drug Administration; LMICs: Low- and middle-income countries; VAS: Value-added services

\section{Acknowledgements}

Not applicable

\section{Authors' contributions}

SAS: conception, design, literature search, drafting of the manuscript, revision of the manuscript. KKSM: conception, design, literature search, drafting of the manuscript, revision of the manuscript. AC: conception, design, literature search, drafting of the manuscript, revision of the manuscript. TS: literature search, drafting of the manuscript, revision of the manuscript. AR: literature search, drafting of the manuscript, revision of the manuscript. MGU: design, revision of the manuscript. $\mathrm{MKH}$ : design, revision of the manuscript. SMNU: conception, supervision and revision of the manuscript. The authors read and approved the final manuscript.

\section{Funding}

Not applicable

\section{Availability of data and materials}

Not applicable

\section{Declarations}

Ethics approval and consent to participate

Not applicable

\section{Consent for publication}

Not applicable

\section{Competing interests}

The authors declare that they have no competing interests.

Received: 2 April 2021 Accepted: 31 May 2021

Published online: 11 June 2021

\section{References}

1. Hu B, Guo H, Zhou P, Shi ZL (2020) Characteristics of SARS-CoV-2 and COVID-19. Nat Rev Microbiol 19(3):1-14. https://doi.org/10.1038/s41579-02000459-7

2. Lu H, Stratton CW, Tang YW (2020) Outbreak of pneumonia of unknown etiology in Wuhan, China: the mystery and the miracle. J Med Virol 92(4): 401-402. https://doi.org/10.1002/jmv.25678

3. World Health Organization (2021) Weekly epidemiological update - 21 February 2021. https://www.who.int/publications/m/item/weeklyepidemiological-update\%2D\%2D-23-february-2021. Accessed 27 February 2021

4. Rakib A, Sami SA, Mimi NJ, Chowdhury MM, Eva TA, Nainu F, Paul A, Shahriar A, Tareq AM, Emon NU, Chakraborty S, Shil S, Mily SJ, Ben Hadda T, Almalki FA, Emran TB (2020) Immunoinformatics-guided design of an epitope-based vaccine against severe acute respiratory syndrome coronavirus 2 spike glycoprotein. Comput Biol Med 124:103967. https://doi.org/10.1016/j.compbiomed.2020.103967
5. Viswanath A, Monga P (2020) Working through the COVID-19 outbreak: rapid review and recommendations for msk and allied heath personnel. J Clin Orthop Trauma 11(3):500-503. https://doi.org/10.1016/j.jcot.2020.03.014

6. Mallhi TH, Liaqat A, Abid A, Khan YH, Alotaibi NH, Alzarea Al, Tanveer N, Khan TM (2020) Multilevel engagements of pharmacists during the COVD-19 pandemic: the way forward. Front. Public Health 8:726. https:/doi.org/10.3389/fpubh.2020.561924

7. Rutter V, Chan AHY, Tuck C, Bader L, Bates I (2018) Weaving the health and pharmaceutical care agenda through the themes of the commonwealth heads of government meeting (CHOGM), London 2018. J Pharm Policy Pract 11(1):10. https://doi.org/10.1186/s40545-018-0140-3

8. Saghir S, Hashmi FK, Khadka S, Rizvi M (2020) Paradigm shift in practice: the role of pharmacists in COVID-19 management. Eurasian J Med 2(2):60-65. https://doi.org/10.46405/ejms.v2i2.93

9. Fitzgerald TJ, Kang Y, Bridges CB, Talbert T, Vagi SJ, Lamont B, Graitcer SB (2016) Integrating pharmacies into public health program planning for pandemic influenza vaccine response. Vaccine 34(46):5643-5648. https://doi. org/10.1016/j.vaccine.2016.09.020

10. Miller S, Patel N, Vadala T, Abrons J, Cerulli J (2012) Defining the pharmacist role in the pandemic outbreak of novel H1N1 influenza. J Am Pharm Assoc 52(6):763-767. https://doi.org/10.1331/JAPhA.2012.11003

11. Stergachis A, Garberson L, Lien O, D'Ambrosio L, Sangaré L, Dold C (2011) Health care workers' ability and willingness to report to work during public health emergencies. Disaster Med Public Health Prep 5(4):300-308. https:// doi.org/10.1001/dmp.2011.77

12. Poudel A, Lau ET, Deldot M, Campbell C, Waite NM, Nissen LM (2019) Pharmacist role in vaccination: evidence and challenges. Vaccine 37(40): 5939-5945. https://doi.org/10.1016/j.vaccine.2019.08.060

13. Adunlin G, Murphy PZ, Manis M (2020) COVID-19: how can rural community pharmacies respond to the outbreak? J Rural Health. 37(1):153-155. https:// doi.org/10.1111/jrh.12439

14. Hedima EW, Adeyemi MS, Ikunaiye NY (2021) Community pharmacists: on the frontline of health service against COVID-19 in LMICs. Res Social Adm Pharm 17(1):1964-1966. https://doi.org/10.1016/j.sapharm.2020.04.013

15. Brewster S, Holt R, Portlock J, Price H (2020) The role of community pharmacists and their position in the delivery of diabetes care: an update for medical professionals. Postgrad Med J 96(1138):473-479. https://doi. org/10.1136/postgradmedj-2020-137511

16. Kretchy IA, Asiedu-Danso M, Kretchy JP (2020) Medication management and adherence during the COVID-19 pandemic: perspectives and experiences from low-and middle-income countries. Res Social Adm Pharm 17(1):20232026. https://doi.org/10.1016/j.sapharm.2020.04.007

17. Bragazzi NL, Mansour M, Bonsignore A, Ciliberti R (2020) The role of hospital and community pharmacists in the management of COVID-19: towards an expanded definition of the roles, responsibilities, and duties of the pharmacist. Pharmacy 8(3):140. https://doi.org/10.3390/pharmacy8030140

18. Todd A, Copeland A, Husband A, Kasim A, Bambra C (2014) The positive pharmacy care law: an area-level analysis of the relationship between community pharmacy distribution, urbanity and social deprivation in England. BMJ open 4(8):e005764. https://doi.org/10.1136/bmjopen-2014-005764

19. Zheng S-q, Yang L, P-x Z, H-b L, Liu F, R-s Z (2020) Recommendations and guidance for providing pharmaceutical care services during COVID-19 pandemic: a China perspective. Res Social Adm Pharm 17(1):1819-1824. https://doi.org/10.1016/j.sapharm.2020.03.012

20. Okereke M, Adebisi YA, Emmanuella N, Jaber HM, Muthoni L, Barka NB (2020) COVID-19: community pharmacy practice in Africa. Int J Health Life Sci 6(2). https://doi.org/10.5812/ijhls.104517

21. Hattingh HL, Sim TF, Parsons R, Czarniak P, Vickery A, Ayadurai S (2016) Evaluation of the first pharmacist-administered vaccinations in Western Australia: a mixed-methods study. BMJ open 6(9):e011948. https://doi.org/1 0.1136/bmjopen-2016-011948

22. Burson RC, Buttenheim AM, Armstrong A, Feemster KA (2016) Community pharmacies as sites of adult vaccination: a systematic review. Hum Vaccines Immunother 12(12):3146-3159. https://doi.org/10.1080/21645515.2016.1215393

23. Al-Quteimat OM, Amer AM (2020) SARS-CoV-2 outbreak: how can pharmacists help? Res Social Adm Pharm 17(2):480-482. https://doi.org/10.1 016/j.sapharm.2020.03.018

24. Phiri MN, Banda M, Mudenda S, Ngazimbi M, Hangoma J, Mufwambi W et al (2020) Coronavirus disease 2019 (COVID-19): the role of pharmacists in the fight against COVID-19 pandemic. Int J Pharm Pharmacol 4(1):1-3. https://doi.org/10.31531/2581-3080.1000143 
25. Liao Y, Ma C, Lau AH, Zhong M (2020) Role of pharmacists during the COVID-19 pandemic in China-Shanghai experiences. J Am Coll Clin Pharm 3(5):997-1002. https://doi.org/10.1002/jac5.1288

26. Patton DE, Cadogan CA, Ryan C, Francis JJ, Gormley GJ, Passmore P, Kerse $\mathrm{N}$, Hughes CM (2018) Improving adherence to multiple medications in older people in primary care: selecting intervention components to address patient-reported barriers and facilitators. Health Expect 21(1):138-148. https://doi.org/10.1111/hex.12595

27. Cadogan CA, Hughes CM (2020) On the frontline against COVID-19: community pharmacists' contribution during a public health crisis. Res Social Adm Pharm 17(1):2032-2035. https://doi.org/10.1016/.sapharm.2020.03.015

28. Amariles P, Ledezma-Morales M, Salazar-Ospina A, Hincapié-García JA (2020) How to link patients with suspicious COVID-19 to health system from the community pharmacies? A route proposal. Res Social Adm Pharm 17(1): 1988-1989. https://doi.org/10.1016/.jsapharm.2020.03.007

29. Okoro RN (2020) COVID-19 pandemic: the role of community pharmacists in chronic kidney disease management supportive care. Res Social Adm Pharm 17(1):1925-1928. https://doi.org/10.1016/j.sapharm.2020.07.008

30. Khatiwada AP, Shrestha S (2020) Pharmacy patronage: identifying the roles of Nepalese pharmacists in tacking COVID-19. J Pure Appl Microbiol 14(suppl 1):937-943. https://doi.org/10.22207/JPAM.14.SPL1.31

31. Ahmad A, Alkharfy KM, Alrabiah Z, Alhossan A (2020) Saudi Arabia, pharmacists and COVID-19 pandemic. J Pharm Policy Pract 13(1):1-3. https://doi.org/10.1186/s40545-020-00243-1

32. Merks P, Jakubowska M, Drelich E, Świeczkowski D, Bogusz J, Bilmin K, Sola KF, May A, Majchrowska A, Koziol M, Pawlikowski J, Jaguszewski M, Vaillancourt R (2020) The legal extension of the role of pharmacists in light of the COVID-19 global pandemic-a review. Res Social Adm Pharm 17(1): 1807-1812. https://doi.org/10.1016/.jsapharm.2020.05.033

33. Adebisi YA, Oke Gl, Ademola PS, Chinemelum IG, Ogunkola IO, LuceroPrisno DE III (2020) SARS-CoV-2 diagnostic testing in Africa: needs and challenges. Pan Afr Med J 35(Suppl 2):4. https://doi.org/10.11604/pamj.202 0.35.4.22703

34. Goff DA, Ashiru-Oredope D, Cairns KA, Eljaaly K, Gauthier TP, Langford BJ (2020) Global contributions of pharmacists during the COVID-19 pandemic. J Am Coll Clin Pharm 3(8):1480-1492. https://doi.org/10.1002/jac5.1329

35. Gross AE, MacDougall C (2020) Roles of the clinical pharmacist during the COVID-19 pandemic. J Am Coll Clin Pharm 3(3):564-566. https://doi.org/10.1 002/jac5.1231

36. Hasan MJ, Nead J (2020) The pandemic COVID-19 and the auspicious role of frontier pharmacists against this global threat. Pharmacol Pharm 11(9): 209-225. https://doi.org/10.4236/pp.2020.119019

37. Ali E, Thulasika P, Sarah A, Cindy T (2020) Pharmacists and COVID-19. J Pharm Policy Pract 13(1):36. https://doi.org/10.1186/s40545-020-00241-3

38. Bukhari N, Rasheed H, Nayyer B, Babar Z-U-D (2020) Pharmacists at the frontline beating the COVID-19 pandemic. J Pharm Policy Pract. 13(1). https://doi.org/10.1186/s40545-020-00210-w

39. Paudyal V, Cadogan C, Fialová D, Henman MC, Hazen A, Okuyan B, Lutters M, Stewart D (2020) Provision of clinical pharmacy services during the COVID-19 pandemic: experiences of pharmacists from 16 European countries. Res Social Adm Pharm. https://doi.org/10.1016/j.sapharm.2020.11.017

40. Jalil MHA, Alsous MM, Hammour KA, Saleh MM, Mousa R, Hammad EA (2020) Role of pharmacists in COVID-19 disease: a Jordanian perspective. Disaster Med Public Health Prep 1-17. 14(6):782-788. https://doi.org/10.101 7/dmp.2020.186

41. Ou H-T, Kao Yang Y-H (2020) Community pharmacists in Taiwan at the frontline against the novel coronavirus pandemic: gatekeepers for the rationing of personal protective equipment. Ann Intern Med 173(2):149-150. https://doi.org/10.7326/M20-1404

42. Singh N, Singh AP, Singh AP (2020) Role of pharmacist towards Covid 19. Curr Opin Infect Dis 1(6):104-106

43. Meghana A, Aparna Y, Chandra SM, Sanjeev S (2020) Emergency preparedness and response (EP\&R) by pharmacy professionals in India: lessons from the COVID-19 pandemic and the way forward. Res Social Adm Pharm 17(1):2018-2022. https://doi.org/10.1016/j.sapharm.2020.04.028

44. Martins MAP, de Medeiros AF, de Almeida CDC, Reis AMM (2020) Preparedness of pharmacists to respond to the emergency of the COVID-19 pandemic in Brazil: a comprehensive overview. Drugs Ther Perspect 36(10): 455-462. https://doi.org/10.1007/s40267-020-00761-7
45. Stevens MP, Patel PK, Nori P (2020) Involving antimicrobial stewardship programs in COVID-19 response efforts: all hands on deck. Infect Control Hosp Epidemiol 41(6):744-745. https://doi.org/10.1017/ice.2020.69

46. Khan Z, Muhammad K, Ahmed A, Rahman H (2020) Coronavirus outbreaks: prevention and management recommendations. Drugs Ther Perspect 36(5): 1-3. https://doi.org/10.1007/s40267-020-00717-x

47. Song Z, Hu Y, Zheng S, Yang L, Zhao R (2020) Hospital pharmacists' pharmaceutical care for hospitalized patients with COVID-19: recommendations and guidance from clinical experience. Res Social Adm Pharm 17(1):2027-2031. https://doi.org/10.1016/j.sapharm.2020.03.027

48. Bhat S, Farraye FA, Moss A (2020) Roles of clinical pharmacists in caring for patients with inflammatory bowel disease during COVID-19. Gastroenterology. 160(5):1880. https://doi.org/10.1053/j.gastro.2020.05.044

49. Meng L, Qiu F, Sun S (2020) Providing pharmacy services at cabin hospitals at the coronavirus epicenter in China. Int J Clin Pharm 2(2):1-4. https://doi. org/10.1007/s1 1096-020-01020-5

50. Siddiqui MA, Abdeldayem A, Dayem KA, Mahomed SH, Diab MJ (2020) Pharmacy leadership during emergency preparedness: insights from the Middle East and South Asia. Am J Health Syst Pharm. 77(15):1191-1194. https://doi.org/10.1093/ajhp/zxaa133

51. Tang BM, Craig JC, Eslick GD, Seppelt I, McLean AS (2009) Use of corticosteroids in acute lung injury and acute respiratory distress syndrome: a systematic review and meta-analysis. Crit Care Med 37(5):1594-1603. https://doi.org/10.1097/CCM.0b013e31819fb507

52. David KB, Adebisi YA (2020) Proposed model for hospital and community pharmacy services during COVID-19 pandemic in Nigeria. Int J Pharm Pract 28(5):544-545. https://doi.org/10.1111/ijpp.12652

53. Visacri MB, Figueiredo IV, de Lima TM (2020) Role of pharmacist during the COVID-19 pandemic: a scoping review. Res Social Adm Pharm 17(1):17991806. https://doi.org/10.1016/j.sapharm.2020.07.003

54. Ying W, Qian Y, Kun Z (2020) Drugs supply and pharmaceutical care management practices at a designated hospital during the COVD-19 epidemic. Res Social Adm Pharm 17(1):1978-1983. https:/doi.org/10.1016/.s.sapharm.2020.04.001

55. Li H, Zheng S, Liu F, Liu W, Zhao R (2020) Fighting against COVID-19: innovative strategies for clinical pharmacists. Res Social Adm Pharm 17(1): 1813-1818. https://doi.org/10.1016/j.sapharm.2020.04.003

56. Langford BJ, So M, Raybardhan S, Leung V, Westwood D, MacFadden DR et al (2020) Bacterial co-infection and secondary infection in patients with COVID-19: a living rapid review and meta-analysis. Clin Microbiol Infect 26(12):1622-1629. https://doi.org/10.1016/..cmi.2020.07.016

57. Schellack N, Coetzee M, Schellack G, Gijzelaar M, Hassim Z, Milne M, Bronkhorst E, Padayachee N, Singh N, Kolman S, Gray AL (2020) COVID-19: guidelines for pharmacists in South Africa. S Afr J Infect Dis 35(1). https:// doi.org/10.4102/sajid.v35i1.206

58. Zeenny RM, Ramia E, Akiki Y, Hallit S, Salameh P (2020) Assessing knowledge, attitude, practice, and preparedness of hospital pharmacists in Lebanon towards COVID-19 pandemic: a cross-sectional study. J Pharm Policy Pract 13(1):1-12. https://doi.org/10.1186/s40545-020-00266-8

59. Khoury P, Azar E, Hitti E (2020) COVID-19 response in Lebanon: current experience and challenges in a low-resource setting. JAMA 324(6):548-549. https://doi.org/10.1001/jama.2020.12695

60. Castro-Balado A, Varela-Rey I, Bandín-Vilar EJ, Busto-Iglesias M, GarcíaQuintanilla L, Mondelo-García C et al (2020) Clinical research in hospital pharmacy during the fight against COVID-19. Farm Hosp 44(7):66-70. https://doi.org/10.7399/fh.11494

61. Jacobi J (2016) Clinical pharmacists: practitioners who are essential members of your clinical care team. Rev méd Clín Las Condes 27(5):571577. https://doi.org/10.1016/j.rmclc.2016.09.002

62. Bajwa MA, Ashiq K (2020) The COVID-19 crisis and supportive role of pharmacists in cancer patients. J Dow Univ Health Sci 14(2):95-96. https:// doi.org/10.36570/jduhs.2020.1.948

63. Arain S, Thalapparambath R, Al Ghamdi FH (2020) COVID-19 pandemic: response plan by the Johns Hopkins Aramco Healthcare inpatient pharmacy department. Res Social Adm Pharm 17(1):2009-2011. https://doi.org/10.1016/.sapharm.2020.05.016

64. Fan A, Kamath M (2020) Comment on Gross and Macdougall "Roles of the clinical pharmacist during the COVID-19 pandemic". J Am Coll Clin Pharm. 3(4). https://doi.org/10.1002/jac5.1252

65. Bhat S, Kehasse A (2020) Additional clinical pharmacists roles during COVID19. J Am Coll Clin Pharm 3(4):825. https://doi.org/10.1002/jac5.1243 
66. Elson EC, Oermann C, Duehlmeyer S, Bledsoe S (2020) Use of telemedicine to provide clinical pharmacy services during the SARS-CoV-2 pandemic. Am J Health Syst Pharm 77(13):1005-1006. https://doi.org/10.1093/ajhp/zxaa112

67. Segal EM, Alwan L, Pitney C, Taketa C, Indorf A, Held L, Lee KS, Son M, Chi M, Diamantides E, Gosser R (2020) Establishing clinical pharmacist telehealth services during the COVID-19 pandemic. Am J Health Syst Pharm. 77(17): 1403-1408. https://doi.org/10.1093/ajhp/zxaa184

68. Liu S, Luo P, Tang M, Hu Q, Polidoro JP, Sun S, Gong Z (2020) Providing pharmacy services during the coronavirus pandemic. Int J Clin Pharm 28(2): 1-6. https://doi.org/10.1007/s11096-020-01017-0

69. Leguelinel-Blache G, Nguyen TL, Louart B, Poujol H, Lavigne JP, Roberts JA, Muller L, Kinowski JM, Roger C, Lefrant JY (2018) Impact of quality bundle enforcement by a critical care pharmacist on patient outcome and costs. Crit Care Med 46(2):199-207. https://doi.org/10.1097/ccm.000000000000282 7

70. Meng L, Huang J, Qiu F, Sun S (2020) Roles of the Chinese clinical pharmacist during the COVID-19 pandemic. J Am Coll Clin Pharm. https:// doi.org/10.1002/jac5.1274

71. Yemm KE, Arnall JR, Cowgill NA (2020) Necessity of pharmacist-driven nonprescription telehealth consult services in the era of COVID-19. Am J Health Syst Pharm 77(15):1188-1188. https://doi.org/10.1093/ajhp/zxaa162

72. Larrouquere L, Gabin M, Poingt E, Mouffak A, Hlavaty A, Lepelley M, Khouri C, Bellier A, Alexandre J, Bedouch P, Bertoletti L, Bordet R, Bouhanick B, Jonville-Bera AP, Laporte S, le Jeunne C, Letinier L, Micallef J, Naudet F, Roustit M, Molimard M, Richard V, Cracowski JL (2020) Genesis of an emergency public drug information website by the French Society of Pharmacology and Therapeutics during the COVID-19 pandemic. Fundam Clin Pharmacol 34(3):389-396. https://doi.org/10.1111/fcp.12564

73. Surapat B, Sungkanuparph S, Kirdlarp S, Lekpittaya N, Chunnguleum K (2021) Role of clinical pharmacists in telemonitoring for patients with Coronavirus Disease 2019 (COVID-19). J Clin Phar Ther 46(1):236-239. https://doi.org/10.1111/jcpt.13293

74. Hussain K, Ambreen G, Muzammil M, Raza SS, Ali U (2020) Pharmacy services during COVID-19 pandemic: experience from a tertiary care teaching hospital in Pakistan. J Pharm Policy Pract 13(1):1-4. https://doi. org/10.1186/s40545-020-00277-5

75. Ayati N, Saiyarsarai P, Nikfar S (2020) Short and long term impacts of COVID19 on the pharmaceutical sector. DARU J Pharm Sci 28(2):1-7. https://doi. org/10.1007/s40199-020-00358-5

76. Le TT, Andreadakis Z, Kumar A, Román RG, Tollefsen S, Saville M et al (2020) The COVID-19 vaccine development landscape. Nat Rev Drug Discov 19(5): 305-306. https://doi.org/10.1038/d41573-020-00073-5

77. The Association of the British Pharmaceutical Industry (2020) What are pharmaceutical companies doing to tackle COVID-19? https://www.abpi.org. uk/medicine-discovery/covid-19/what-are-pharmaceutical-companies-doingto-tackle-the-disease/. Accessed 11 November 2020

78. Albarrak Al, Mohammed R, Al Elayan A, Al Fawaz F, Al Masry M, Al Shammari M et al (2019) Middle East Respiratory Syndrome (MERS): comparing the knowledge, attitude and practices of different health care workers. J Infect Public Health 14(1):89-96. https://doi.org/10.1016/j.jiph.2019.06.029

79. Ta QTH, Nadeem MF, Matti N, Parveen S, Jawad M (2020) COVID-19 and role of pharmacist in correctional facilities. Res Social Adm Pharm 17(1):20422043. https://doi.org/10.1016/j.sapharm.2020.07.024

80. The European Federation of Pharmaceutical Industries and Associations (2020) WeWontRest in the fight against COVID-19. https://www.efpia.eu/ covid-19/. Accessed 27 October 2020

81. Watson KE, Singleton JA, Tippett V, Nissen LM (2019) Defining pharmacists' roles in disasters: a Delphi study. PloS one 14(12):e0227132. https://doi.org/1 0.1371/journal.pone.0227132

82. Elbeddini A, Wen CX, Tayefehchamani Y, To A (2020) Mental health issues impacting pharmacists during COVID-19. J Pharm Policy Pract 13(1):1-6. https://doi.org/10.1186/s40545-020-00252-0

83. Ashiru-Oredope D, Chan AHY, Olaoye O, Rutter V (2020) Needs assessment and impact of COVD-19 on pharmacy professionals in 31 commonwealth countries. J Pharm Policy Pract 13(1):1-11. https://doi.org/10.21203/rs.3.rs-64723/v1

84. Mak VS, Lee SW, March G (2018) Pharmacists' roles in nursing homes in Malaysia. J Pharm Policy Pract 48(5):493-494. https://doi.org/10.1002/ jppr.1443

85. Cheong MWL, Brock T, Karwa R, Pastakia SD (2020) COVID-19 and clinical pharmacy worldwide-a wake up call and a call to action. J Am Coll Clin Pharm. https://doi.org/10.1002/jac5.1286
86. Hasan SS, Kow CS, Zaidi STR (2020) Social distancing and the use of PPE by community pharmacy personnel: does evidence support these measures? Res Social Adm Pharm 17(2):456-459. https://doi.org/10.1016/j.sapharm.202 0.04 .033

87. Rana W, Mukhtar S, Mukhtar S (2020) COVID-19 in Pakistan: current status, challenges and recommendations. J Clin Med Kaz 3(57):48-52. https://doi. org/10.23950/1812-2892-JCMK-00766

88. Manyama TL, Tshitake RM, Moloto NB (2020) The role of pharmacists in the renal multidisciplinary team at a tertiary hospital in South Africa: strategies to increase participation of pharmacists. Health SA Gesondheid 25:1-7. https://doi.org/10.4102/hsag.v25i0.1357

89. Cheong MW (2020) "To be or not to be in the ward": the impact of COVID19 on the role of hospital-based clinical pharmacists-a qualitative study. J Am Coll Clin Pharm 3(8):1458-1463. https://doi.org/10.1002/jac5.1315

90. Bauman JL (2020) Hero clinical pharmacists and the COVID-19 pandemic: overworked and overlooked. J Am Coll Clin Pharm. 3(4):721-722. https://doi. org/10.1002/jac5.1246

91. Scahill S, Tracey M, Sayers J, Warren L (2018) Being healthcare provider and retailer: perceiving and managing tensions in community pharmacy. J Pharm Practi Res 48(3):251-261. https://doi.org/10.1002/jppr.1410

92. Emanuel EJ, Persad G, Upshur R, Thome B, Parker M, Glickman A, Zhang C, Boyle C, Smith M, Phillips JP (2020) Fair allocation of scarce medical resources in the time of COVID-19. N Engl J Med 382(21):2049-2055. https:// doi.org/10.1056/NEJMsb2005114

93. Neumann JL, Mau L-W, Virani S, Denzen EM, Boyle DA, Boyle NJ, Dabney J, de KeselLofthus A, Kalbacker M, Khan T, Majhail NS, Murphy EA, Paplham P, Parran L, Perales MA, Rockwood TH, Schmit-Pokorny K, Shanafelt TD, Stenstrup E, Wood WA, Burns LJ (2018) Burnout, moral distress, work-life balance, and career satisfaction among hematopoietic cell transplantation professionals. Biol Blood Marrow Transplant 24(4):849-860. https://doi.org/1 0.1016/j.bbmt.2017.11.015

94. El Hadidi S, Samir Bazan N, Byrne S, Darweesh E, Bermingham M (2020) Heart failure prescribing quality at discharge from a critical care unit in Egypt: the impact of multidisciplinary care. Pharmacy 8(3):159. https://doi. org/10.3390/pharmacy8030159

95. Gavin B, Hayden J, Adamis D, McNicholas F (2020) Caring for the psychological well-being of healthcare professionals in the COVID-19 pandemic crisis. Ir Med J 113(4):51

96. McGregor S, Henderson KJ, Kaldor JM (2014) How are health research priorities set in low and middle income countries? A systematic review of published reports. PloS one 9(10):e108787. https://doi.org/10.1371/journal. pone. 0108787

97. Scahill S (2014) Barriers to effective pharmacy practice in low-and middleincome countries. Integr Pharm Res Pract 3:25-27. https://doi.org/10.2147/ IPRP.S35379

98. Atif M, Razzaq W, Mushtaq I, Malik I, Razzaq M, Scahill S et al (2020) Pharmacy services beyond the basics: a qualitative study to explore perspectives of pharmacists towards basic and enhanced pharmacy services in Pakistan. Int J Environ Res Public Health 17(7):2379. https://doi.org/10.11 86/s40545-020-00240-4

99. Atif M, Malik I (2020) COVID-19 and community pharmacy services in Pakistan: challenges, barriers and solution for progress. J Pharm Policy Pract 13(1):1-4. https://doi.org/10.1186/s40545-020-00240-4

100. Sabry N, El Hadidi S, Kamel A, Abbassi M, Farid S (2021) Awareness of the Egyptian public about COVID-19: what we do and do not know. Inform Health Soc Care:1-12. https://doi.org/10.1080/17538157.2021.1883029

101. Pinto GS, Hung M, Okoya F, Uzman N (2021) FIP's response to the COVID-19 pandemic: global pharmacy rises to the challenge. Res Social Adm Pharm 17(1):1929-1933. https://doi.org/10.1016/j.sapharm.2020.07.004

102. Hussain R, Dawoud DM (2020) Drive-thru pharmacy services: a way forward to combat COVID-19 pandemic. Res Social Adm Pharm 17(1):1920-1924. https://doi.org/10.1016/j.sapharm.2020.07.015

\section{Publisher's Note}

Springer Nature remains neutral with regard to jurisdictional claims in published maps and institutional affiliations. 